\title{
Facile Preparation of Polyimine Vitrimers with Enhanced Creep Resistance, Thermal and Mechanical Properties via Metal Coordination
}

Sheng Wang, ${ }^{\text {a,b }}$ Songqi Ma, ${ }^{\text {a* }}$ Qiong Li,,${ }^{\text {a,b }}$ Xiwei Xu, ${ }^{a}$ Binbo Wang, ${ }^{a}$ Kaifeng Huang, ${ }^{a}$ Yanlin

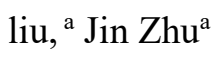

${ }^{a}$ Key laboratory of bio-based polymeric materials technology and application of Zhejiang province, Ningbo Institute of Materials Technology and Engineering, Chinese Academy of Sciences, Ningbo 315201, P. R. China

${ }^{\mathrm{b}}$ University of Chinese Academy of Sciences, Beijing 100049, P. R. China

*Corresponding authors: (Songqi Ma) E-mail masongqi@nimte.ac.cn, Tel 86-574-87619806

\section{Content}

Figure S1. Non isothermal DSC curves of the polyimine-metal complex vitrimers

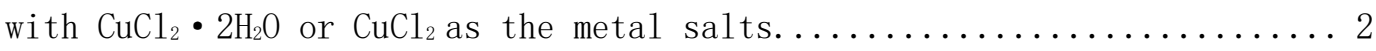
Figure S2. (a) Structure of model compound lig A; (b) The two possible structural conformers of $\operatorname{lig} \mathrm{A}$. The relative energies (in kcal mol${ }^{-1}$ ) are

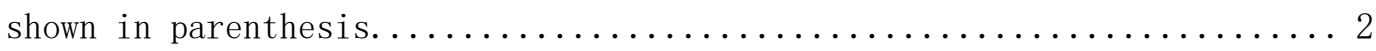

Figure S3. Digital photos of the polyimine-metal complex vitrimers. ..... 3 Figure S4. TEM images of $\mathrm{P}-\mathrm{Cu} 5, \mathrm{P}-\mathrm{Mg} 5$ and $\mathrm{P}-\mathrm{Fe} 5 \ldots \ldots \ldots \ldots \ldots \ldots \ldots$ Figure S5. Temperature-dependent FTIR spectra of (d) P-Cu5, (e) P-Mg5 and

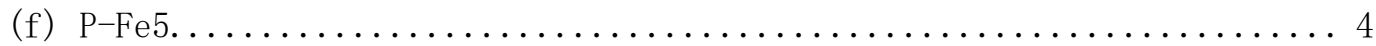
Figure S6. ${ }^{1} \mathrm{H}$ NMR spectra of the extracts from the vitrimers during swelling

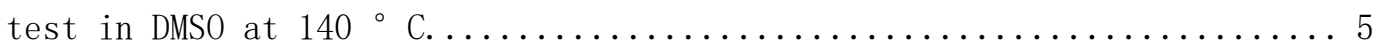
Figure S7. Stress relaxation curves of P-Cu5, P-Fe5 and P-Mg5 at $190^{\circ}$ C. 6 Figure S8. DMA curves of $\mathrm{P}-\mathrm{Cu} 5$ before and after two cycles reprocessing. . 6 Figure S9. Stability of $\mathrm{P}-0$ and $\mathrm{P}-\mathrm{Cu} 5$ in different solvents at room

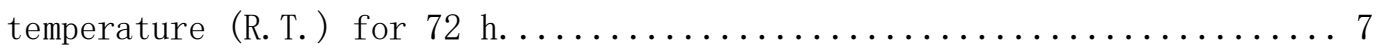

Figure S10. Contact angle of $\mathrm{P}-0$ and $\mathrm{P}-\mathrm{Cu} 5$ in water.............. 8 Figure S11. UV-Vis absorption spectrum of $\mathrm{P}-\mathrm{Cu} 5$ extracts in water. .....8 8 Figure S12. ${ }^{1} \mathrm{H}$ NMR spectrum of P-Cu5 extracts during stability test in DMSO.

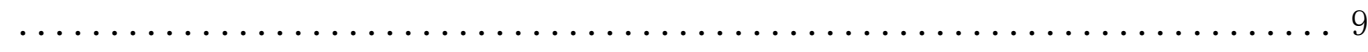

Table S1. TGA Data of the polyimine vitrimers.................. 9 


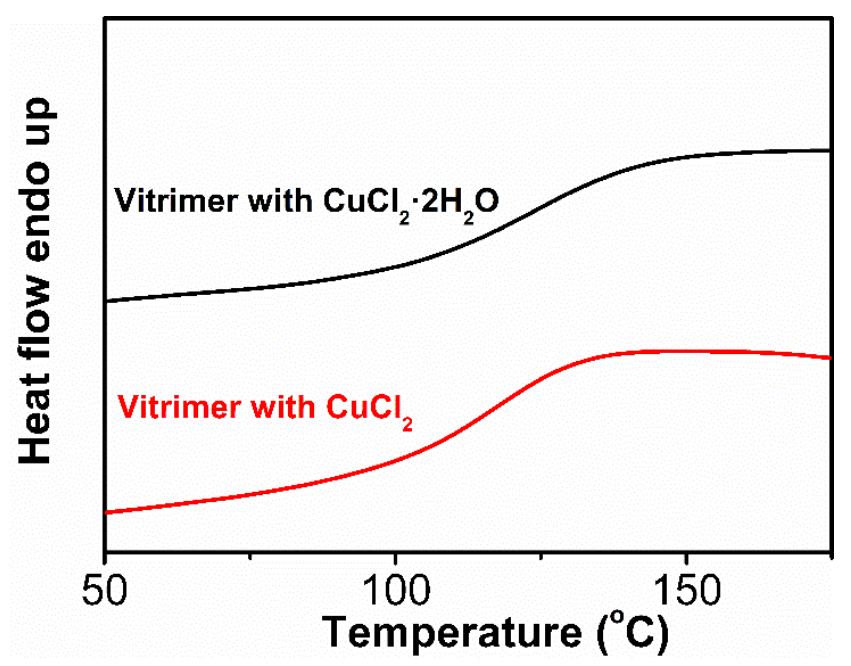

Figure S1. Non isothermal DSC curves of the polyimine-metal complex vitrimers with $\mathrm{CuCl}_{2} \cdot 2 \mathrm{H}_{2} \mathrm{O}$ or $\mathrm{CuCl}_{2}$ as the metal salts.

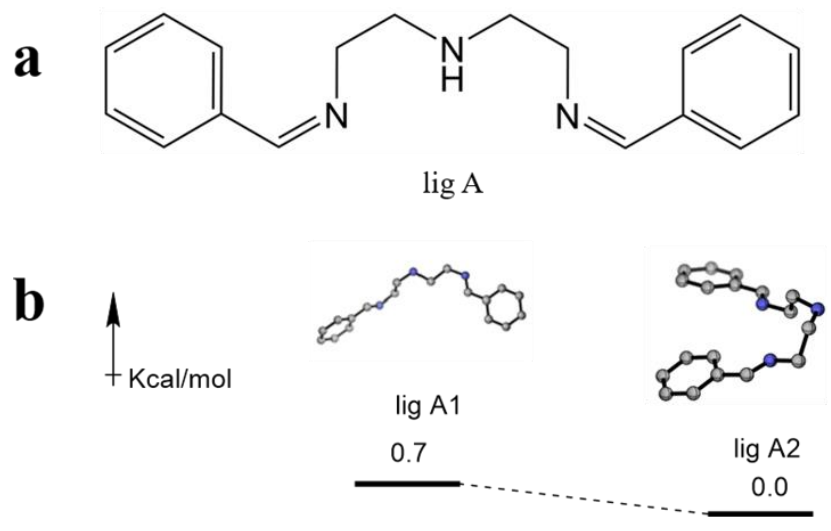

Figure S2. (a) Structure of model compound lig A; (b) The two possible structural conformers of lig A. The relative energies (in $\mathrm{kcal} \mathrm{mol}^{-1}$ ) are shown in parenthesis. 


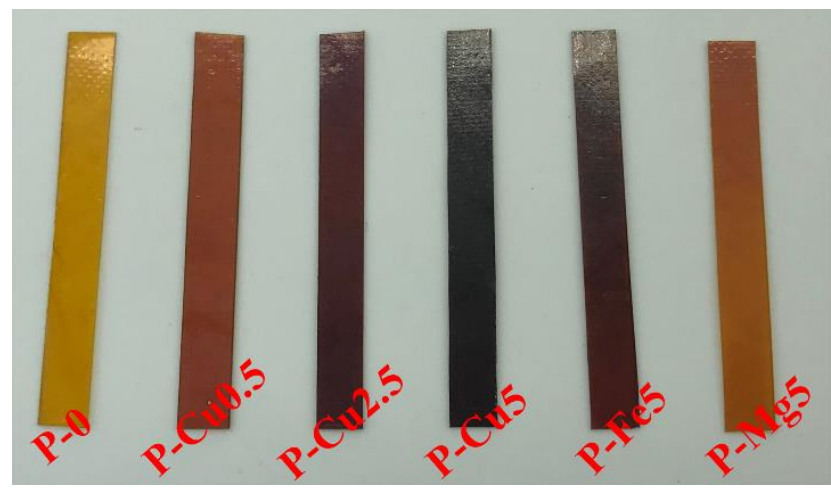

Figure S3. Digital photos of the polyimine-metal complex vitrimers.
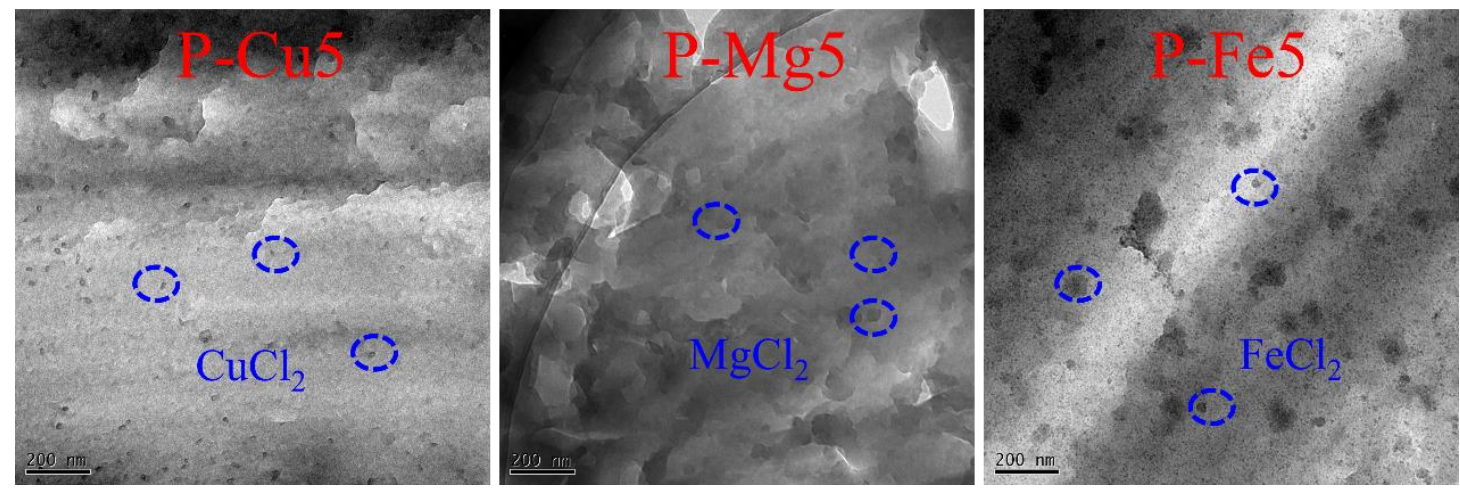

Figure S4. TEM images of P-Cu5, P-Mg5 and P-Fe5. 

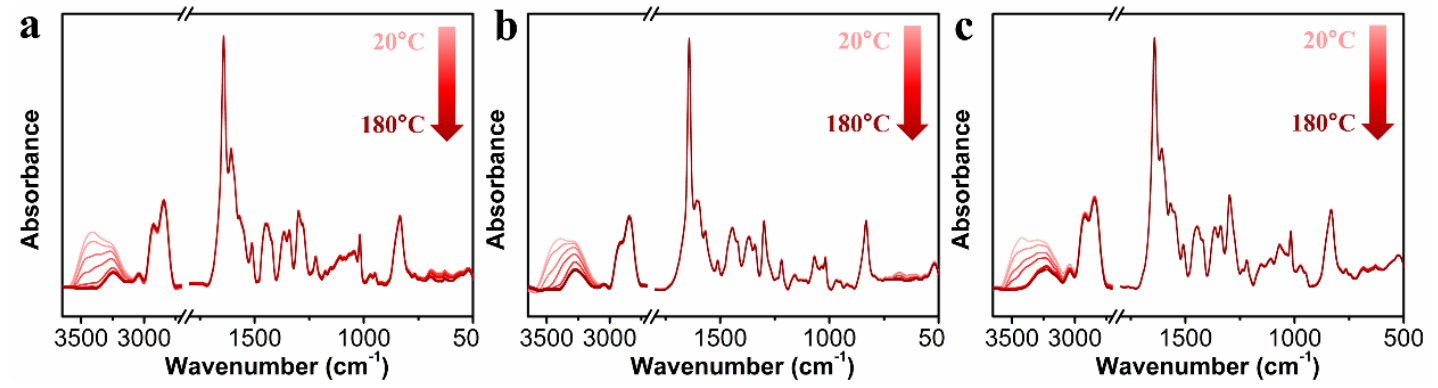

Figure S5. Temperature-dependent FTIR spectra of (d) P-Cu5, (e) P-Mg5 and (f) P-Fe5.

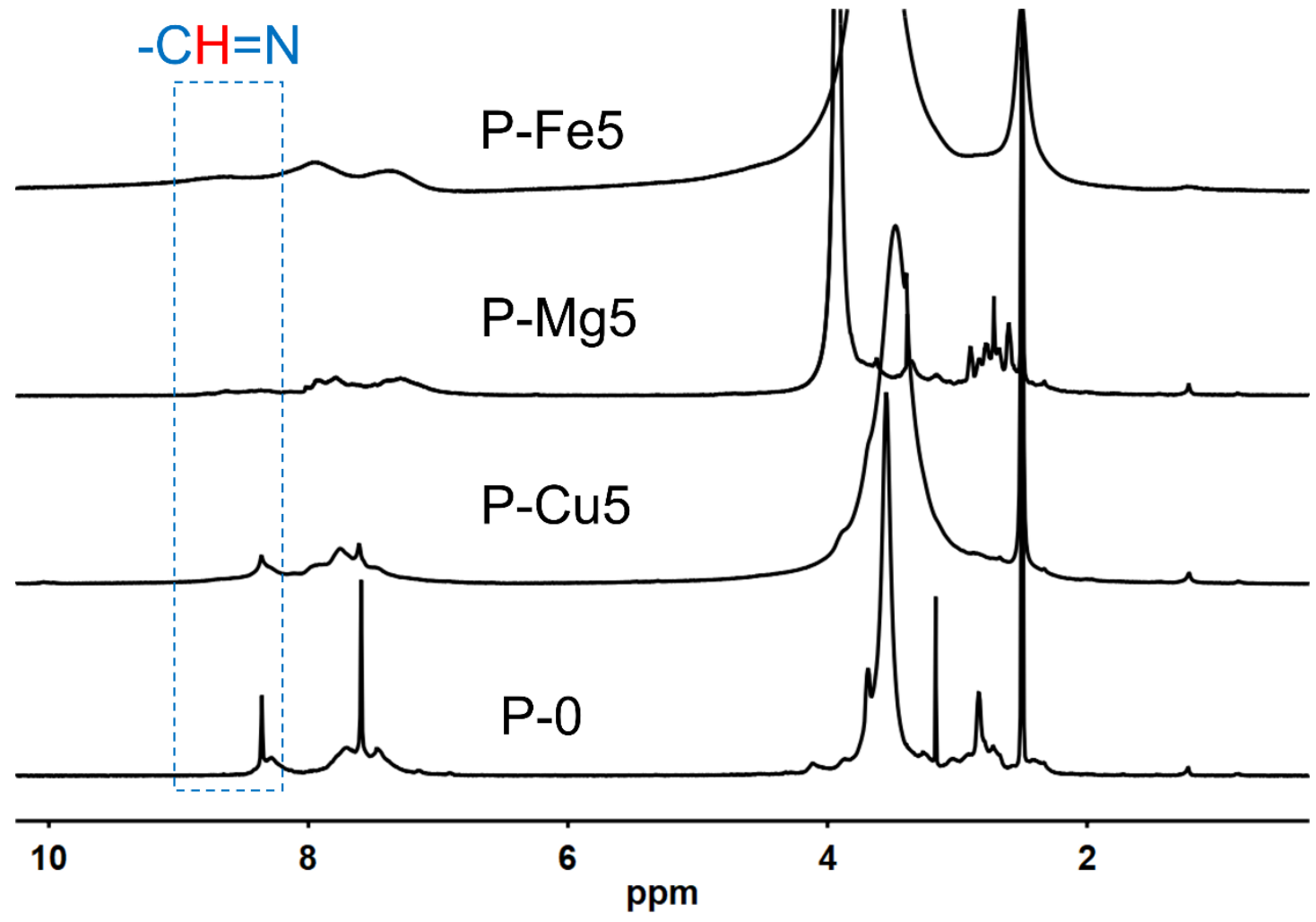


Figure S6. ${ }^{1} \mathrm{H}$ NMR spectra of the extracts from the vitrimers during swelling test in DMSO at $140{ }^{\circ} \mathrm{C}$.

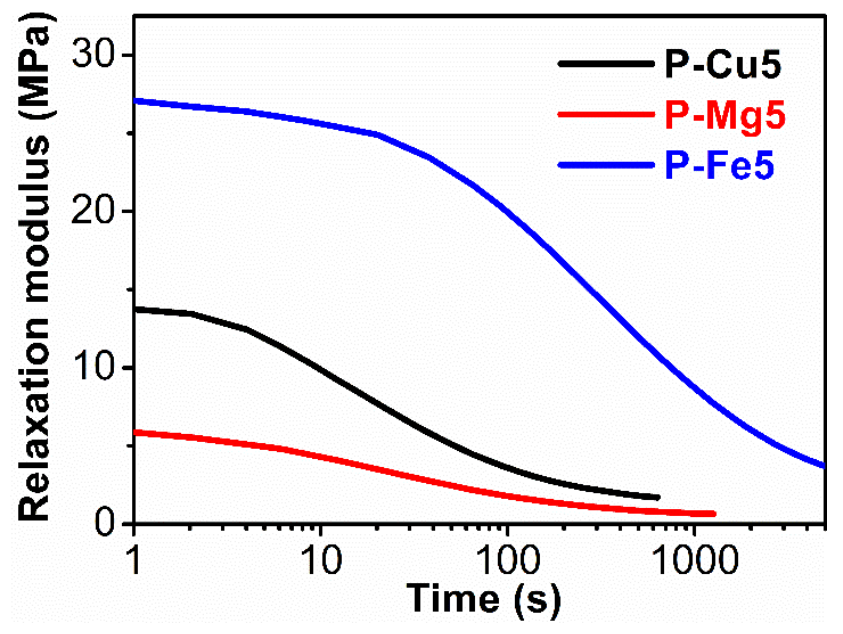


Figure S7. Stress relaxation curves of P-Cu5, P-Fe5 and P-Mg5 at $190{ }^{\circ} \mathrm{C}$.
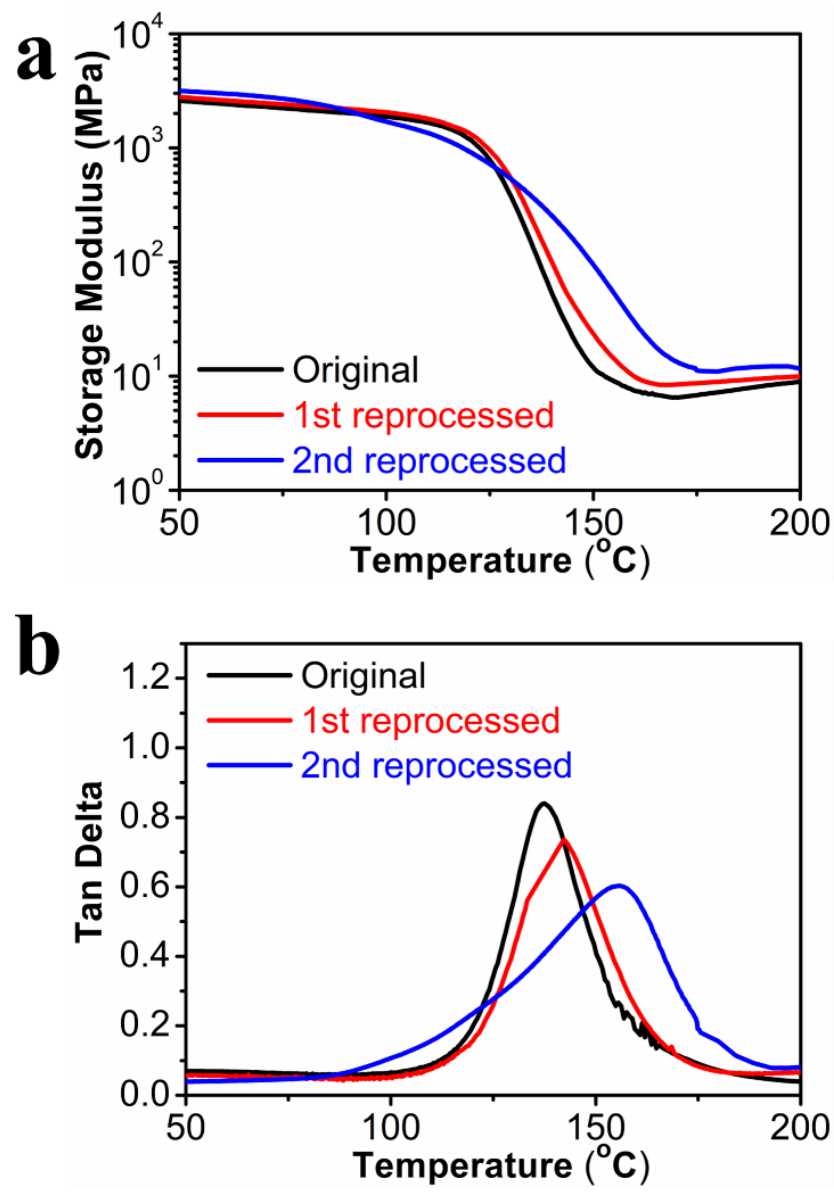

Figure S8. DMA curves of P-Cu5 before and after two cycles reprocessing. 

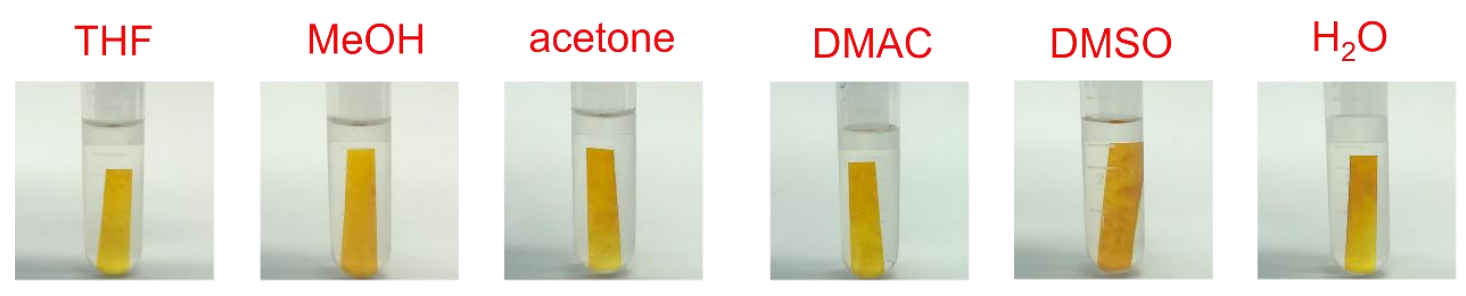

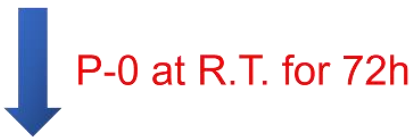
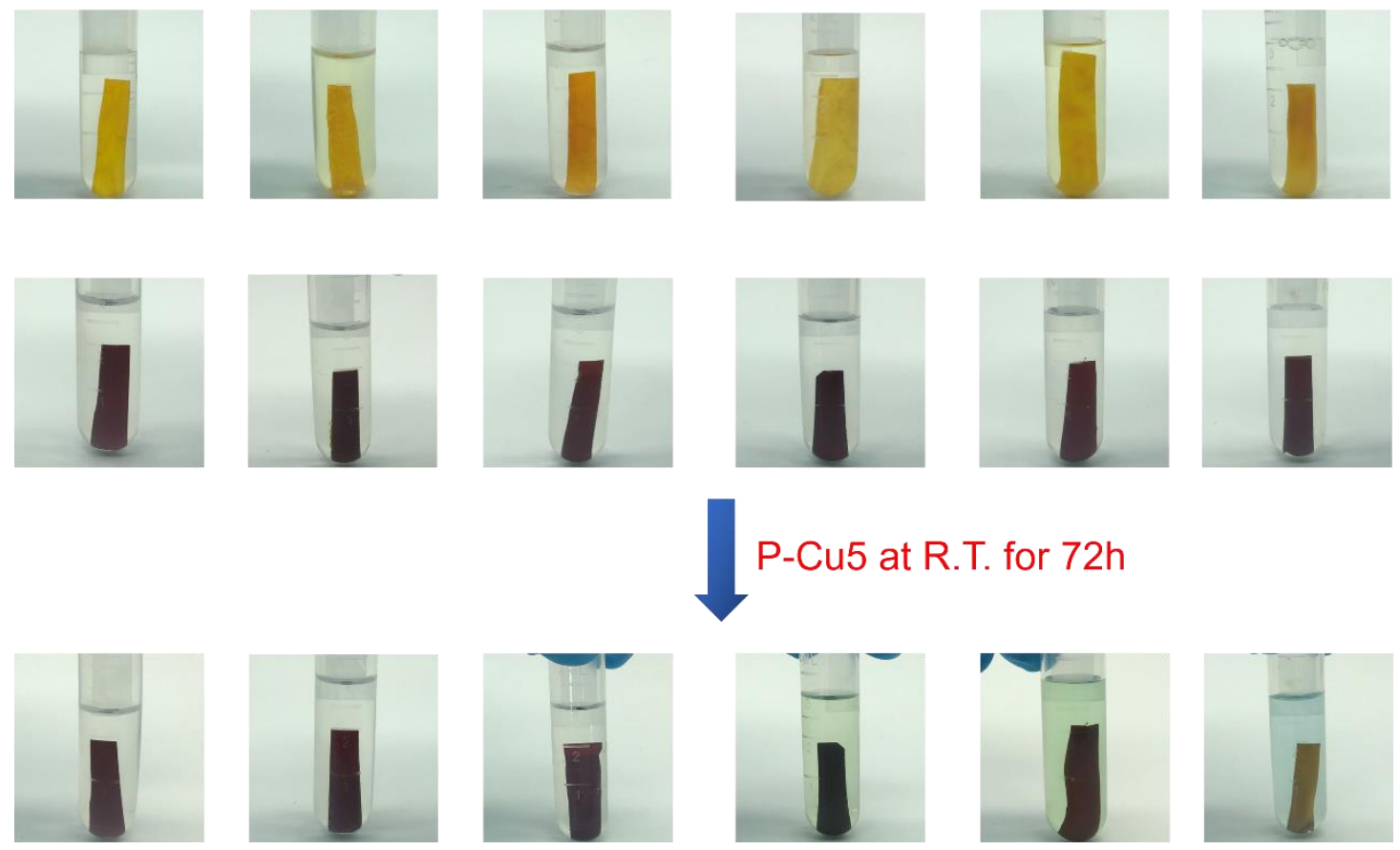

Figure S9. Stability of P-0 and P-Cu5 in different solvents at room temperature (R.T.) for $72 \mathrm{~h}$. 


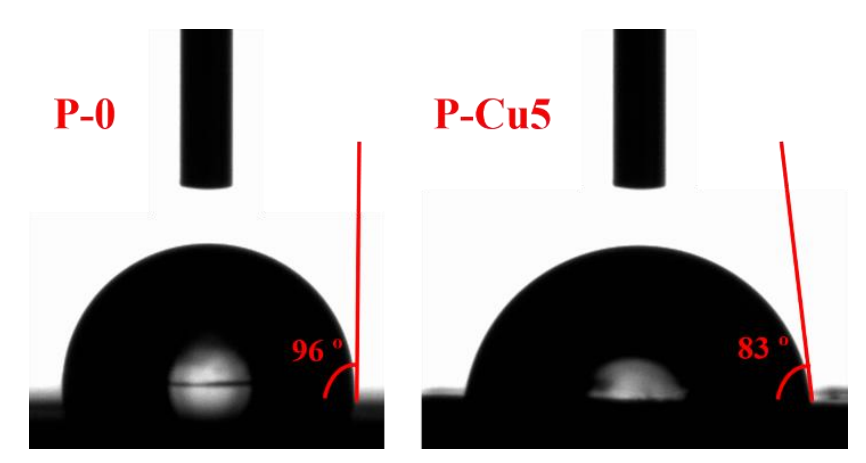

Figure S10. Contact angle of P-0 and P-Cu5 in water.

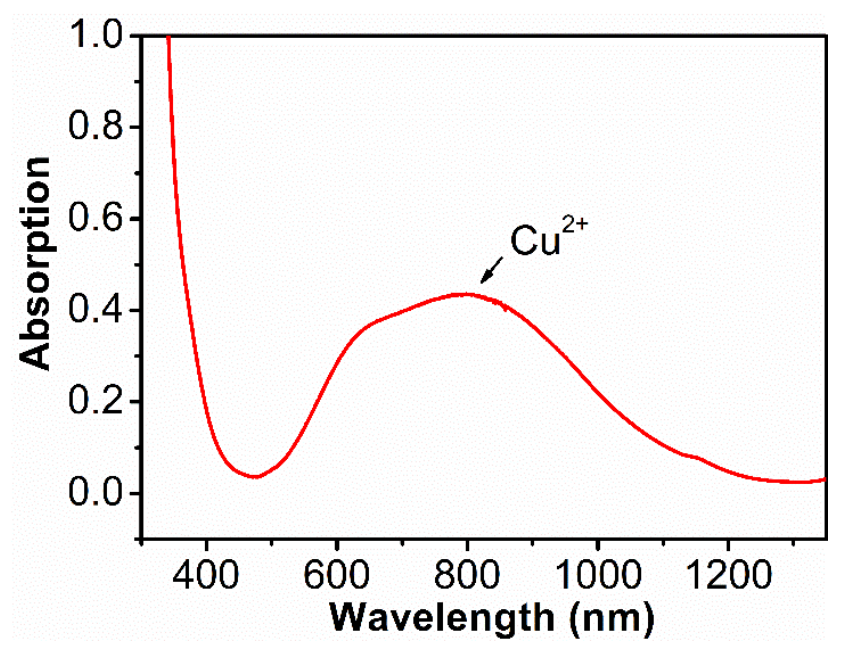

Figure S11. UV-Vis absorption spectrum of P-Cu5 extracts in water. 


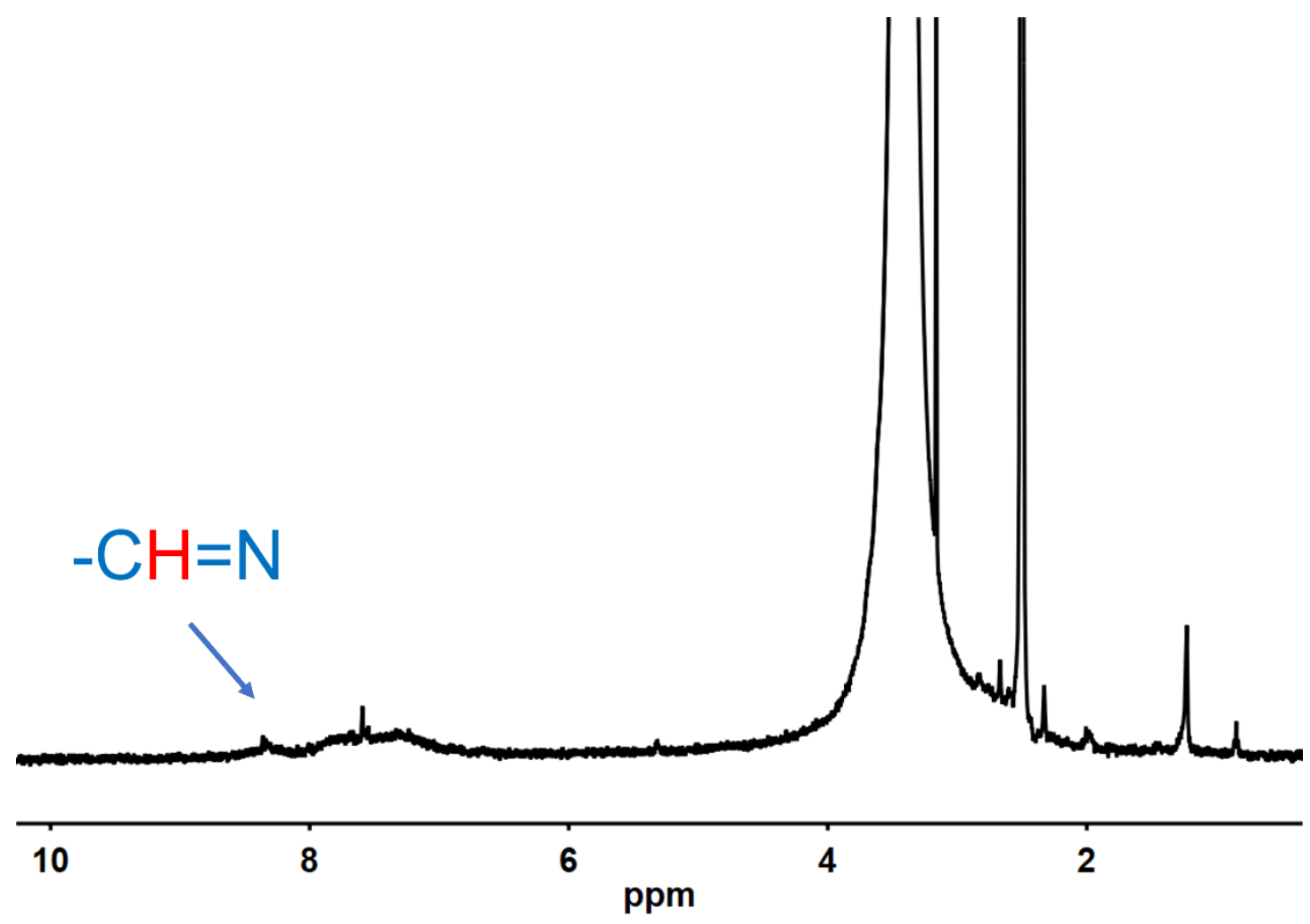

Figure S12. ${ }^{1} \mathrm{H}$ NMR spectrum of P-Cu5 extracts during stability test in DMSO.

Table S1. TGA Data of the polyimine vitrimers.

\begin{tabular}{cccc}
\hline Sample & $T_{d 5 \%}\left({ }^{\circ} \mathrm{C}\right)$ & $T_{d 30 \%}\left({ }^{\circ} \mathrm{C}\right)$ & $R_{700}(\%)$ \\
\hline P-0 & 278 & 422 & 39.4 \\
P-Cu0.5 & 278 & 416 & 39.8 \\
P-Cu2.5 & 281 & 400 & 42.4 \\
P-Cu5 & 282 & 412 & 44.2 \\
P-Mg5 & 281 & 395 & 40.2 \\
P-Fe5 & 289 & 401 & 45.4 \\
\hline
\end{tabular}

